\title{
Establishment of brown anoles (Anolis sagrei) across a southern California county and potential interactions with a native lizard species
}

\author{
Samuel R. Fisher ${ }^{\text {Corresp., } 1}{ }^{\text {, Lelani A. Del Pinto }}{ }^{1}$, Robert N. Fisher ${ }^{2}$ \\ ${ }^{1}$ Department of Biology, La Sierra University, Riverside, CA, United States \\ 2 Western Ecological Research Center, US Geological Survey, San Diego, CA, USA \\ Corresponding Author: Samuel R. Fisher \\ Email address: sfis086@lasierra.edu
}

The brown anole, Anolis sagrei, is a native species to the Caribbean; however, A. sagrei has invaded multiple parts of the United States, including Florida, Louisiana, Hawai'i, and more recently California. The biological impacts of $A$. sagrei invading California are currently unknown. Evidence from the invasion in Taiwan shows that they spread quickly and when immediate action is not taken eradication stops being a viable option. In Orange County, California, five urban sites, each less than 100 ha, were surveyed for an average of $49.2 \mathrm{~min}$. Approximately $200 \mathrm{~A}$. sagrei were seen and verified across all survey sites. The paucity of native lizards encountered during the surveys within these sites suggests little to no overlap between the dominant diurnal western fence lizard, Sceloporus occidentalis, and $A$. sagrei. This notable lack of overlap could indicate a potentially disturbing reality that $A$. sagrei are driving local extirpations of $S$. occidentalis. 
Establishment of brown anoles (Anolis sagrei) across a southern California county and potential interactions with a native lizard species

3

4

5

6

7 992101 USA

10

11 Corresponding Author:

12 Samuel R. Fisher ${ }^{1}$

13

14

15

16 92505 USA
8 2U.S. Geological Survey, Western Ecological Research Center, San Diego, California, USA

Samuel R. Fisher ${ }^{1}$, Lelani A. Del Pinto ${ }^{1}$, and Robert N. Fisher ${ }^{2}$

${ }^{1}$ Department of Biology, La Sierra University, 4500 Riverwalk Pkwy, Riverside California, USA

Email address: sfis086@lasierra.edu 
17 Abstract

18 The brown anole, Anolis sagrei, is a native species to the Caribbean; however, A. sagrei has

19 invaded multiple parts of the United States, including Florida, Louisiana, Hawai'i, and more

20 recently California. The biological impacts of $A$. sagrei invading California are currently

21 unknown. Evidence from the invasion in Taiwan shows that they spread quickly and when

22 immediate action is not taken eradication stops being a viable option. In Orange County,

23 California, five urban sites, each less than 100 ha, were surveyed for an average of $49.2 \mathrm{~min}$.

24 Approximately $200 \mathrm{~A}$. sagrei were seen and verified across all survey sites. The paucity of native

25 lizards encountered during the surveys within these sites suggests little to no overlap between the

26 dominant diurnal western fence lizard, Sceloporus occidentalis, and A. sagrei. This notable lack

27 of overlap could indicate a potentially disturbing reality that $A$. sagrei are driving local

28 extirpations of $S$. occidentalis.

29

30

Keywords: Invasive species, Anolis, Norops sagrei, Polychrotidae, Sceloporus, Sceloporus occidentalis, California

\section{Introduction}

The brown anole, Anolis sagrei, is a recently reported invasive species to California (Mahrdt, Ervin, \& Nafis, 2014). While this species is a native to Cuba, the Bahamas, additional Caribbean islands, and eastern Mesoamerica, $A$. sagrei has also recently invaded Taiwan likely by way of the plant trade (Norval et al., 2016; Reynolds et al., 2020). The invasion in Taiwan is increasingly widespread and eradication is seemingly no longer an effective option (Norval et al., 2016). Other countries invaded by A. sagrei include Anguilla, Bermuda, Grand Cayman, Ecuador, Grenada, Jamaica, Mexico (even though it is native on the east coast), Singapore, St. Vincent, and Turks and Caicos (Kraus 2009; Amador et al., 2017; Reynolds et al., 2020). In the United States, A. sagrei has invaded multiple states, including Florida, Louisiana, Texas, and Hawai'i (Kolbe et al., 2004; Kraus, 2009). The Citizen Scientist tool iNaturalist, (https://www.inaturalist.org/; verified July 15, 2019) shows approximately 25 states in the USA with verified records of $A$. sagrei, although not all states have confirmed established populations and many probably could not establish based on climate factors.

The first published record of $A$. sagrei from California in 2014 indicated a breeding population with many individuals detected rapidly at the initial site and adjacent houses (Mahrdt, Ervin, \& Nafis, 2014). Due to the rapid growth of citizen science reporting tools, we assessed Orange County for localities for this species and found there are less than ten reports of $A$. sagrei in iNaturalist, two from H.E.R.P. (http://www.naherp.com/) and one from HerpMapper (https://www.herpmapper.org/: verified July 15, 2019; Spear, Pauley \& Kaiser, 2017). Studies show that $A$. sagrei is a robust invertebrate and small lizard predator which is known to change the behavior of lizards in similar ecological niches (Losos \& Spiller, 1999; Kamath \& Stuart, 2015; Stroud, Giery \& Outerbridge, 2017). In its invasive range in Taiwan, A. sagrei has also been known to change native ant communities as well as feed on native lizard species (Norval, 2007; Norval et al., 2016). In Bermuda where A. sagrei is an invasive, approximately 2200 individuals are estimated in a 2.27-ha site (Stroud, Giery, \& Outerbridge, 2017). Furthermore, $A$. sagrei is a highly adaptive lizard, able to obtain larger population densities $(>12,000$ per ha) in as few as four years when it is introduced (Campbell \& Echternacht, 2003). To illustrate how dramatic an irruption this is, Campbell \& Echternacht (2003) started with less than twenty $A$. sagrei per uninhabited island, and after four years the $A$. sagrei population of one island was 
63

64

65

66

67

68

69

70

71

72

73

reported to be over 500 estimated individuals (Campbell \& Echternacht, 2003). Additionally, $A$. sagrei is shown to be able to exponentially expand its range allowing for large increases in the areas they reside (Kolbe et al., 2004). Invasive A. sagrei have the seeming potential to change how the natural community functions in the habitats where they typically invade. This is especially worrisome in California, a biodiversity hotspot, that is highly susceptible to reptile invasions (Li et al., 2016).

There is concern that in California that $A$. sagrei will change the biodiversity of the urban ecological communities where they currently reside and continue to spread into native habitats. One specific concern is that the scrublands and chaparral of southern California will match well with $A$. sagrei native habitat and their "trunk-ground" ecomorphology, indicating that it is well suited to these native microhabitats (Losos, 2011), although precipitation differences between the native range and California would seem to be a barrier to establishment. In California these habitats are heavily utilized by the native California western fence lizard, Sceloporus occidentalis, which occupies a similar niche as A. sagrei in its native range (Ashbury \& Adolph, 2007; Losos, 2011). Additionally, S. occidentalis is also well known to occur in the same type of urban areas as A. sagrei in California (Grolle, Lopez \& Gerson, 2014; Sparkman et al., 2018; Putman et al., 2019). Sceloporus occidentalis was known to be widespread and mostly continuous in distribution across central Orange County, which includes our study areas. Our paper focuses on the question of whether A. sagrei is able to obtain these high-density populations locally within this short period of occupancy in southern California, and whether there is any evidence of its displacement of native $S$. occidentalis within the urban areas that $A$. sagrei have already occupied. Since $S$. occidentalis (mass average in southern California approximately $11.18 \mathrm{gm}$; Asbury \& Adolph, 2007) is a much larger lizard than A. sagrei (average mass approximately 5.01 gm; Campbell \& Echternacht, 2003), we would not hypothesize that $A$. sagrei would displace the native species.

\section{Materials and Methods}

Surveys were conducted throughout Orange County sites (Figs. 1-5) based on observations from iNaturalist (July 20, 2019), H.E.R.P. (http://www.naherp.com/; July 20, 2019), HerpMapper (https://www.herpmapper.org/; July 20, 2019), as well as a new population discovered through a separate survey of lizards. We used daytime visual encounter surveys at the various study sites where $A$. sagrei had been detected within the past five years. While $A$. sagrei has been noted at as many as eight separate localities, this study only looked at five main invasion sites where observations for $S$. occidentalis were recorded nearby via iNaturalist and H.E.R.P. and public access was available. All localities were urban sites within Orange County. The five Orange County study localities are: Site 1, 33.721487, -117.826076 (Fig. 1), a 1.7-ha business complex next to a stream culvert; Site 2,33.700801,-117.787705 (Fig. 2), a 90-ha residential neighborhood; Site 3, 33.799126,-117.800109 (Fig. 3), a 20-ha neighborhood patch bordering native habitat; Site 4, 33.701028, -117.91848 (Fig. 4), a hospital and shopping complex, 10 ha in size; and Site 5, 33.881758, -117.828688 (Fig. 5), a different 20-ha residential neighborhood patch (Table 1). Each site within Orange County was surveyed once for a minimum of 40 minutes by two observers typically. Surveys were conducted from 30 June 2019 to 1 August 2019. Observations took place from 11:20 am to $8: 30 \mathrm{pm}$. The main objective of the survey was to find and record any signs of high-density A. sagrei. When a population of A. sagrei was assessed, we walked around the site to map (circumscribe) the size of the minimum convex polygon of the occupied patch. Our secondary objective was to map the locations of $S$. 
109 occidentalis relative to these invasive lizards as evidence for displacement. We also recorded all

110

111

112

113

114

115

116

117

118

119

120

121

122

123

124

125

126

127

128

129

130

131

132

133

134

135

136

137

138

139

140

141

142

143

144

145

146

147

148

149

150

151

152

153

154 additional squamates encountered during the surveys.

\section{Results}

Of the five localities surveyed, A. sagrei were detected at all sites (Table 1 and Figs. 1-5). All size classes of $A$. sagrei were also observed at each site. We found plant nurseries were present within the invaded areas for three of the five sites. Across all sites there was no spatial overlap detected between $A$. sagrei and $S$. occidentalis. The closest proximity in which we found the two species was $10 \mathrm{~m}$ apart at Site 5 on the outskirts of the suspected invasion front. We also found no A. sagrei perching higher than $2.5 \mathrm{~m}$ with most perching at a height of $0-1.0 \mathrm{~m}$, a trend followed by $S$. occidentalis as well. At other sites where both species were detected $S$. occidentalis could be found within the occupied area, but never within the area occupied by $A$. sagrei. The $A$. sagrei individuals appeared to be continuously distributed within these invaded urban habitats. We detected over 50 ha of habitat occupied by this species across the five sites. Below are the specific results for each site.

At Site 1 (surveyed on June $30^{\text {th }}$ ), A. sagrei were detected throughout the small area and were extremely quick to seek cover. The survey lasted 40 min beginning at 6:05 pm and ending at $6: 45 \mathrm{pm}, 30 \mathrm{~A}$. sagrei observations were made, at a rate of approximately 0.75 per min. Conversely, we recorded $14 \mathrm{~S}$. occidentalis, at a rate of 0.07 per min from 3:25 pm to 6:45 pm. The $A$. sagrei population was discovered at 6:05 pm thus the shorter survey effort for that species. There was no overlap between the A. sagrei patch and S. occidentalis, which was only detected around the boundaries of the patch occupied by $A$. sagrei. This site was calculated to be approximately 0.8 ha (Fig. 1). Site 2 (surveyed July $5^{\text {th }}$ ) was searched for $68 \mathrm{~min}$ beginning at $12: 53 \mathrm{pm}$ and resulted in $41 \mathrm{~A}$. sagrei at a rate of 0.6 per min, and two total $S$. occidentalis at a rate of 0.03 per min. This site had a minimum area of 26 ha (Fig. 2). Site 3 (surveyed on July $22^{\text {nd }}$ ) was searched for 42 min starting at 11:20 am and resulted in 57 total A. sagrei at a rate of 1.36 per min, with 7 total $S$. occidentalis detected at a rate of 0.17 per min. This site had a minimum area of 10 ha and contained a plant nursery (Fig. 3). Site 4 (surveyed on July $5^{\text {th }}$ ) was searched for 43 min starting at 2:34 pm and a total of $14 \mathrm{~A}$. sagrei were recorded at an average of 0.33 per min. At this site we found zero $S$. occidentalis. This site had a minimum of 8.5 ha and contained a plant nursery within the site (Fig. 4). Site 5 (surveyed on August $1^{\text {st }}$ ) was searched for $53 \mathrm{~min}$ at $6: 45 \mathrm{pm}$. A total of $60 \mathrm{~A}$. sagrei were recorded at a rate of 1.13 per min plus $15 \mathrm{~S}$. occidentalis were recorded at a rate of 0.25 per min. This site had a minimum area of five ha and contained a plant nursery within the focal area. For this site we mapped all anole locations to illustrate how dense they were within the invaded area (Fig. 5). We compared our rates of discovery against those of the previous California study (Mahrdt et al., 2014); their rate of finding $A$. sagrei averaged 0.23 per min whereas our mean rate of 0.55 (range $0.33-1.36$ ) A sagrei per min.

\section{Discussion}

Our results show that established populations of $A$. sagrei existed at these five sites, and these populations appeared to be expanding. We measured over 50 ha total of invaded land across these five study sites, within which the largest population utilized at least 26 ha. Furthermore, our results show a lack of $S$. occidentalis within the core areas of $A$. sagrei occupancy, but $S$. occidentalis are detectable on the boundaries of the invasion epicenters. There was no direct overlap in distribution at less than $5 \mathrm{~m}$, and no interactions were observed between these two 
155 species. Since $A$. sagrei have $3 \mathrm{~m}^{2}$ territories we do not consider this geospatial overlap (Losos, 156 2011). We also found that we had an observation rate of almost double the number $A$. sagrei per 157 min than the only published record for California by Mahrdt et al. (2014) also during July. This 158 suggests that, as the various populations become more established, the number of individuals and 159 their detectability are increasing (Table 1). Both species were found to be utilizing the same habitats. Most were on the ground (sidewalk, walkways, or driveways), on rocks and stones in yards, along rock or cinderblock walls, or on the base of trees or shrubs. Although this was not quantified, these lizards appeared to be utilizing generally the same perches but were geospatially non-overlapping. This habitat shift and lower perch use in the urban environment for S. occidentalis has recently been documented in the literature (Putman et al., 2019).

Sceloporus occidentalis is a widespread species in southern California but has been shown to be affected by road fragmentation leading to genetic changes across habitat patches (Delaney, Riley, \& Fisher, 2010; Brehme et al., 2013). Although S. occidentalis is a common urban lizard, anything that impacts its ability to navigate these landscapes could further fragment these urban and native populations. This native species also has a significant role in the tickLyme disease dynamics on the west coast of the United States, particularly within California (Lane \& Quistad, 1998). While $S$. occidentalis is a key species on which the Ixodes pacificus tick nymphs feed, it also controls the spread of Lyme disease by killing the spirochete Borrelia burgdorferi with chemical elements in their blood when the I. pacificus nymphs feed on them (Lane \& Loye, 1989; Lane \& Quistad, 1998). Any negative interactions from this anole invasion may have the potential to change mechanisms of the tick-Lyme disease interaction in southern California (Swei et al., 2011). There is some evidence to suggest mechanisms could be changing with Lyme disease detected in dog sera of urban San Diego dogs in the highest prevalence, compared to natural habitats, suggesting that changes in S. occidentalis populations could be relevant to disease prevalence change over time, even in the urban landscape (Olson et al., 2000).

While there are a few reported records of $A$. sagrei on the west coast of the United States, no large spatial population estimates have been previously mapped and documented. The only published record documents an establishment within an acre of invaded area and mentions that it has expanded to additional properties (Mahrdt, Ervin \& Nafis, 2014). It is possible that within the urban environment, road size is helping to act as a delimiter for how fast and far $A$. sagrei can spread, as this is the case for S. occidentalis (Campbell \& Echternacht, 2003; Delaney, Riley, $\&$ Fisher, 2010). Moisture or water could also be a limiting factor, and these lizards might remain restricted to nursery and urban areas where landscaping is supported by subsidized water leading to artificially high moisture levels. The closest documented large $A$. sagrei population to California is located more than $1500 \mathrm{~km}$ away in Texas. There are also large established populations in Hawai'i, which could be contributing to the spread of A. sagrei through lack of strong biosecurity on plant shipments coming into California, especially given the correlation between sites with $A$. sagrei containing nurseries. Interception of this species by biosecurity authorities in New Zealand has presumably precluded establishment there (Chapple et al., 2016).

Finding solutions to contain and manage $A$. sagrei in southern California will be an important step in controlling this species. Further steps would include determining the invasion pathways for source populations, which likely includes nursery plants as has been previously reported (Norval et al., 2002; Kraus 2009). Three of our five study sites have nursery areas located within the invasion area, which seem to be a good indicator of the presence of $A$. sagrei, supporting this hypothesis. Evidence in the literature of plant nurseries involvement in introducing invasive species could help prompt the creation of quarantine areas (such as for 
201 coqui frogs in Hawai'i). Looking at the specific impacts $A$. sagrei will have on the southern

202 California ecological landscape will be an important research aid in the management of this

203 invasive species, especially if compared to $S$. occidentalis. We hypothesize that one way to

204 understand the trophic role of $A$. sagrei is to use isotopes to look at their trophic level within the

205 urban landscape, to determine if they are serving as spider or ant specialists, as described in the

206 literature; this could then be also compared to $S$. occidentalis (Norval et al., 2010; Giery et al.,

207 2014). Potential investments of money and time might be needed to look at the true extent and

208 potential for removal of $A$. sagrei in southern California. Finally, continual monitoring and

209 mapping of $A$. sagrei invaded sites as well as their spread will aid in the long term as these

210 strategies are developed.

211

\section{Conclusions}

213 We show that Anolis sagrei is rapidly invading Orange County California with over 50 hectares

214 of currently occupied habitats. It is apparently displacing the native Sceloporus occidentalis

within areas where it is irrupting. This invasion is surprising as $A$. sagrei is a much more tropical adapted lizard and was not predicted to be able to invade arid southern California. Urban landscaping with subsidized water sources may explain this invasion in addition to dispersal via the nursery trade. The displacement of $S$. occidentalis could disrupt the Lyme disease mitigation offered by this native species thus changing the disease dynamics in these invaded urban areas. Quarantine areas might need to be established rapidly as well as any removal experiments prior to further spread of this invasive species.

\section{Acknowledgements}

We thank Marie Vicario-Fisher and Jesse L. Grismer for reviewing a draft of the manuscript and Will Flaxington for location information. We additionally want to thank Victor and Phyllis Fisher for lodging support. We thank USGS Ecosystems Mission Area and the Wildlife Program Area for project support. Any use of trade, firm, or product names is for descriptive purposes only and does not imply endorsement by the U.S. Government.

\section{Funding}

Funding for manuscript writing was provided by USGS Ecosystems Mission Area and the Wildlife Program Area through annual funding to R. Fisher. Research was funded through La Sierra University, Riverside California.

\section{Competing interests}

We acknowledge we have no competing interests.

\section{Author contributions}

S.R.F designed study, collected data, analyzed data, wrote and revised manuscript, created figures 1-5. L.A.D.P designed study, collected data, analyzed data, wrote and revised manuscript. R.N.F designed study, collected data, analyzed data, wrote and revised manuscript.

\section{References}

Asbury, D. A., \& Adolph, S. C. (2007). Behavioural plasticity in an ecological generalist: microhabitat use by western fence lizards. Evolutionary Ecology Research, 9: 801-815. 
246

247

248

249

250

251

252

253

254

255

256

257

258

259

260

261

262

263

264

265

266

267

268

269

270

271

272

273

274

275

276

277

278

279

280

281

282

283

284

Brehme, C. S., J.A. Tracey, L. R. McClenaghan, \& R. N. Fisher. (2013). Permeability of roads to movement of scrubland lizards and small mammals. Conservation Biology, 27:710-720. DOI: $10.1111 /$ cobi.12081

Campbell, T. S., \& Echternacht, A. C. (2003). Introduced species as moving targets: changes in body sizes of introduced lizards following experimental introductions and historical invasions. Biol Invasions, 5(3), 193-212.

Chapple, D. G., Knegtmans, J., Kikillus, H., \& Van Winkel, D. (2016). Biosecurity of exotic reptiles and amphibians in New Zealand: building upon Tony Whitaker's legacy. J of the Royal Society of New Zealand, 46(1), 66-84.

Delaney K. S., S. P. D. Riley, \& R. N. Fisher. (2010). A rapid, strong, and convergent genetic response to urban habitat fragmentation in four divergent and widespread vertebrates. PLoS ONE, 5(9): e12767. doi: 10.1371/journal.pone.0012767.

Giery, S. T., Lemoine, N. P., Hammerschlag-Peyer, C. M., Abbey-Lee, R. N., \& Layman, C. A. (2014). Bidirectional trophic linkages couple canopy and understory food webs. Functional Ecology, 27, 1436-1441.

Grolle, E. K., Lopez, M. C., \& Gerson, M. M. (2014). Flight initiation distance differs between populations of western fence lizards (Sceloporus occidentalis) at a rural and an urban site. Bulletin, Southern California Academy of Sci, 113(1), 42-47.

Kamath, A., \& Stuart, Y. E. (2015). Movement rates of the lizard Anolis carolinensis (Squamata: Dactyloidae) in the presence and absence of Anolis sagrei (Squamata: Dactyloidae). Breviora, 546(1), 1-8.

Kolbe, J. J., Glor, R. E., Schettino, L. R., Lara, A. C., Larson, A., \& Losos, J. B. (2004). Genetic variation increases during biological invasion by a Cuban lizard. Nature, 431(7005), 177.

Kraus, F. (2009). Alien reptiles and amphibians: a scientific compendium and analysis (Vol. 4). Springer Science \& Business Media.

Lane, R. S., \& Quistad, G. B. (1998). Borreliacidal factor in the blood of the western fence lizard (Sceloporus occidentalis). The J of Parasitology, 84(1), 29-34.

Lane, R. S., \& Loye, J. E. (1989). Lyme disease in California: interrelationship of Ixodes pacificus (Acari: Ixodidae), the western fence lizard (Sceloporus occidentalis), and Borrelia burgdorferi. J of Medical Entomol, 26(4), 272-278.

Li, X., Liu, X., Kraus, F., Tingley, R., \& Li, Y. (2016). Risk of biological invasions is concentrated in biodiversity hotspots. Frontiers in Ecol and the Environment, 14(8), 411417.

Losos, J. B. (2011). Lizards in an evolutionary tree: ecology and adaptive radiation of anoles (Vol. 10). Univ of California Press.

Losos, J. B., \& Spiller, D. A. (1999). Differential colonization success and asymmetrical interactions between two lizard species. Ecol, 80(1), 252-258.

Mahrdt, C.R., E.L. Ervin and G. Nafis. (2014). Geographic distribution: Anolis sagrei (Cuban Brown Anole). Herpetol Rev, 45: 658-659.

Peer) reviewing PDF | (2019:12:43887:1:1:NEW 9 Mar 2020) 
285

286

287

288

289

290

291

292

293

294

295

296

297

298

299

300

301

302

303

304

305

306

307

308

309

310

311

312

313

314

315

316

317

318

319

320

321

322

323

324

325

Norval, G., Mao, J.-J., Chu, H.-P., \& L.C. Chen. 2002. A new record of an introduced species, the brown anole (Anolis sagrei) (Dumeril \& Bibron, 1837), in Taiwan. Zoological Studies, 41:332-336.

Norval, G. (2007). A report on male Anolis sagrei saurophagy in Chiayi County, Taiwan. Herpetol Bulletin, 102:34-37.

Norval, G., Hsiao, W. F., Huang, S. C., \& Chen, C. K. (2010). The diet of an introduced lizard species, the brown anole (Anolis sagrei), in Chiayi County, Taiwan. Russ J Herpetol, 17(2), 131-138.

Norval, G., Wang, G., Mao, J., Liu, L., Chuang, M., Yang, Y., Slater, K., Brown, L. (2016). The known distribution of a lizard, the brown anole (Anolis sagrei Dumeril \& Bibron, 1837), in Taiwan. IRFC Reptiles and Amphibians Journal, 23(1):62-67

Olson, P. E., Kallen, A. J., Bjorneby, J. M., \& Creek, J. G. (2000). Canines as sentinels for Lyme disease in San Diego County, California. J of Veterinary Diagnostic Investigation, 12(2), 126-129.

Putman, B. J., Gasca, M., Blumstein, D. T., \& G. B. Pauly. (2019). Downsizing for downtown: limb lengths, toe lengths, and scale counts decrease with urbanization in western fence lizards (Sceloporus occidentalis). Urban Ecosystems, 22, 1071-1081.

Reynolds, R. G., Kolbe, J. J., Glor, R. E., Lopez-Darias, M., Gomez Pourroy, C. V., Harrison, A. S., de Queiroz, K., Revell, L. J., \& J. Losos. (2020). Phylogeographic and phenotypic outcomes of brown anole colonization across the Caribbean provide insight into the beginning stages of an adaptive radiation. Journal of Evolutionary Biology, DOI: $10.1111 /$ jeb. 13581 .

Sparkman, A., Howe, S., Haynes, S., Hobbs, B., \& Handal. K. (2018). Parallel behavioral and morphological divergence in fence lizards on two college campuses. PLoS ONE, 13(2), e0191800.

Spear, D. M., Pauly, G. B., \& Kaiser, K. (2017). Citizen science as a tool for augmenting museum collection data from urban areas. Frontiers in Ecol and Evolution, 5, 86.

Stroud, J. T., Giery, S. T., \& Outerbridge, M. E. (2017). Establishment of Anolis sagrei on Bermuda represents a novel ecological threat to Critically Endangered Bermuda skinks (Plestiodon longirostris). Biol Invasions, 19(6), 1723-1731.

Swei, A., Ostfeld, R. S., Lane, R. S., \& Briggs, C. J. (2011). Impact of the experimental removal of lizards on Lyme disease risk. Proceedings of the Royal Society B: Biological Sciences, 278(1720), 2970-2978.

Peer] reviewing PDF | (2019:12:43887:1:1:NEW 9 Mar 2020) 
326

327

328

329

330

331

332

333

334

335

336

337

338

339

340

341

342

343

344

345

346

347

348

349

350

351

352

353

354

355

356

357

358

359

360

\section{Table Legends:}

Table 1. Sites surveyed for Brown Anoles (Anolis sagrei) and Western Fence Lizards (Sceloporus occidentalis) from Orange County, California, and published data from San Diego County.

\section{Figure Legends:}

Figure 1. Site 1 surveyed for A. sagrei and S. occidentalis. The pink polygon represents the minimum convex polygon where $A$. sagrei was found in the invaded areas. The yellow squares represent $S$. occidentalis individuals detected during these surveys. Google Earth image (C) 2020 Google.

Figure 2. Site 2 surveyed for A. sagrei and S. occidentalis. The pink polygon represents the minimum convex polygon where $A$. sagrei was found in the invaded areas. The yellow squares represent $S$. occidentalis individuals detected during these surveys. Google Earth image (C) 2020 Google.

Figure 3. Site 3 surveyed for A. sagrei and S. occidentalis. The pink polygon represents the minimum convex polygon where $A$. sagrei was found in the invaded areas. The yellow squares represent $S$. occidentalis individuals detected during these surveys. The blue polygon identifies a plant nursery. Google Earth image (C) 2020 Google.

Figure 4. Site 4 surveyed for $A$. sagrei and S. occidentalis. The pink polygon represents the minimum convex polygon where $A$. sagrei was found in the invaded areas. No $S$. occidentalis individuals detected during these surveys. The blue polygon identifies a plant nursery. Google Earth image (C) 2020 Google.

Figure 5. Site 5 surveyed for A. sagrei and S. occidentalis. The pink polygon represents the minimum convex polygon where $A$. sagrei was found in the invaded areas. This figure illustrates all of the anole locations (yellow circles), each circle could represent up to three observations of anoles. The yellow squares represent up to three $S$. occidentalis individuals detected during these surveys. The blue polygon identifies a plant nursery. Google Earth image (C) 2020 Google. 


\section{Table $\mathbf{1}$ (on next page)}

Sites surveyed for Brown Anoles (Anolis sagrei) and Western Fence Lizards (Sceloporus occidentalis) from Orange County, California, and published data from San Diego County. 
1 Table 1. Sites surveyed for Brown Anoles (Anolis sagrei) and Western Fence Lizards (Sceloporus occidentalis) from Orange County,

2 California, and published data from San Diego County.

\begin{tabular}{|c|c|c|c|c|c|c|c|c|c|c|c|c|c|c|c|}
\hline 汽 & 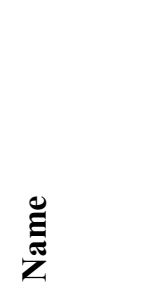 & 己े & & 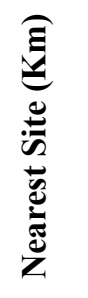 & 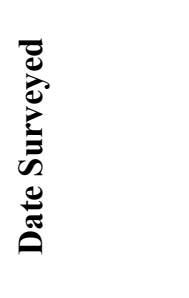 & 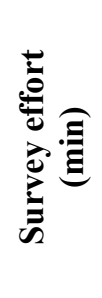 & 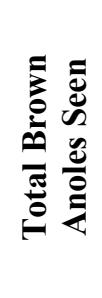 & 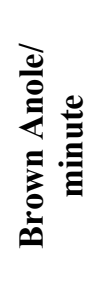 & 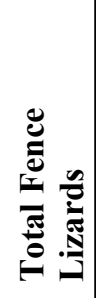 & 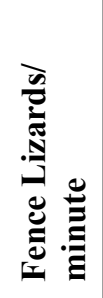 & 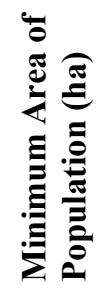 & 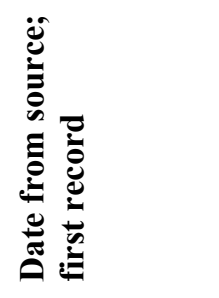 & 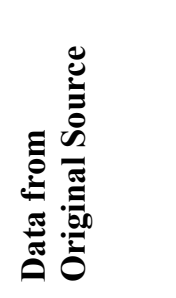 & 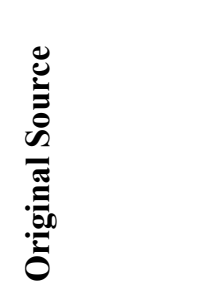 & 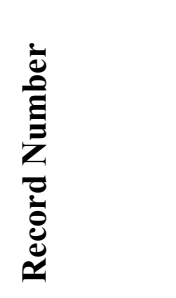 \\
\hline Site 1 & $\begin{array}{l}\text { Starbucks } \\
\text { Edinger }\end{array}$ & Orange & $\begin{array}{c}33.721487 \\
-117.826076\end{array}$ & 4 & 30-Jun-19 & $\begin{array}{l}40 / \\
200\end{array}$ & 30 & 0.75 & 14 & 0.07 & 0.8 & 30-Jun-19 & 30 & This study & - \\
\hline Site 2 & $\begin{array}{l}\text { Irvine } \\
\text { High } \\
\text { School }\end{array}$ & Orange & $\begin{array}{c}33.700801 \\
-117.787705\end{array}$ & 4 & 5-Jul-19 & 68 & 41 & 0.6 & 2 & 0.03 & 26 & 8-Sep-17 & 2 records & iNaturalist & 8004416 \\
\hline Site 3 & Bond Ave & Orange & $\begin{array}{c}33.799126, \\
-117.800109\end{array}$ & 9 & 22-Jul-19 & 42 & 57 & 1.36 & 7 & 0.16 & 10 & 18-Jun-16 & $\sim 4$ dozen & H.E.R.P. & 259001 \\
\hline Site 4 & Macarthur & Orange & $\begin{array}{l}33.701028, \\
-117.91848\end{array}$ & 9 & 5-Jul-19 & 43 & 14 & 0.33 & 0 & 0 & 8.5 & 16-Apr-18 & 1 & iNaturalist & 11177594 \\
\hline Site 5 & $\begin{array}{l}\text { Yorba } \\
\text { Linda }\end{array}$ & Orange & $\begin{array}{c}33.881758, \\
-117.828688\end{array}$ & 9.5 & 1-Aug-19 & 53 & 60 & 1.13 & 15 & 0.25 & 7 & 20-Jul-19 & $5+$ & iNaturalist & 29180552 \\
\hline $\begin{array}{l}\text { Previous } \\
\text { Study }\end{array}$ & Escondido & \begin{tabular}{|l|} 
San \\
Diego
\end{tabular} & $\begin{array}{c}33.17544 \\
-117.23656\end{array}$ & 77.5 & 19-Jul-14 & 120 & 28 & 0.23 & - & - & - & 19-Jul-14 & 28 & $\begin{array}{l}\text { Marhdt et al. } \\
2014\end{array}$ & - \\
\hline
\end{tabular}




\section{Figure 1}

Site 1 surveyed for $A$. sagrei and S. occidentalis.

The red polygon represents the minimum convex polygon where $A$. sagrei was found in the invaded areas. The green dots represent $S$. occidentalis individuals detected during these surveys. 


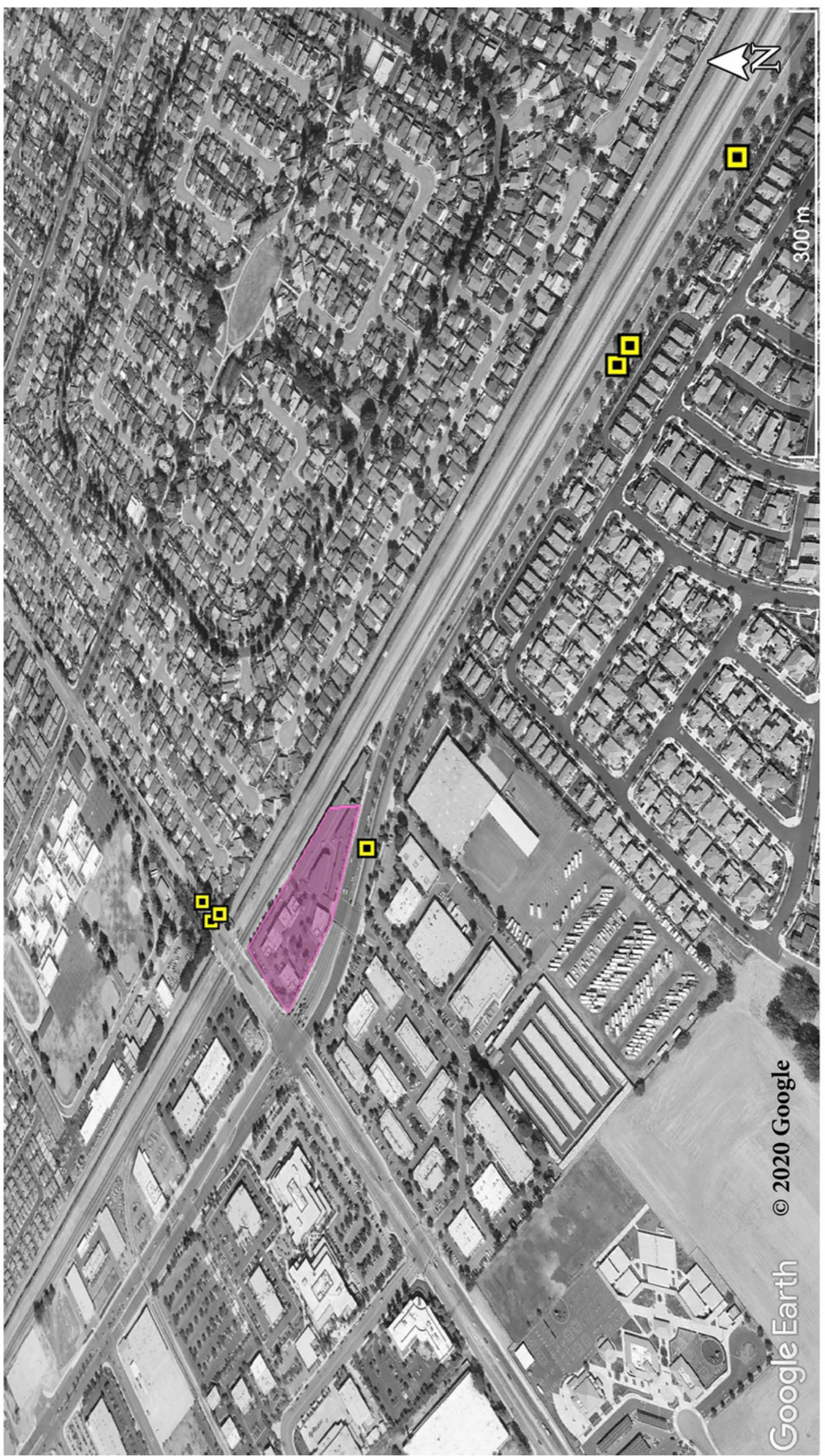


Figure 2

Site 2 surveyed for $A$. sagrei and S. occidentalis.

The red polygon represents the minimum convex polygon where $A$. sagrei was found in the invaded areas. The green dots represent $S$. occidentalis individuals detected during these surveys. 


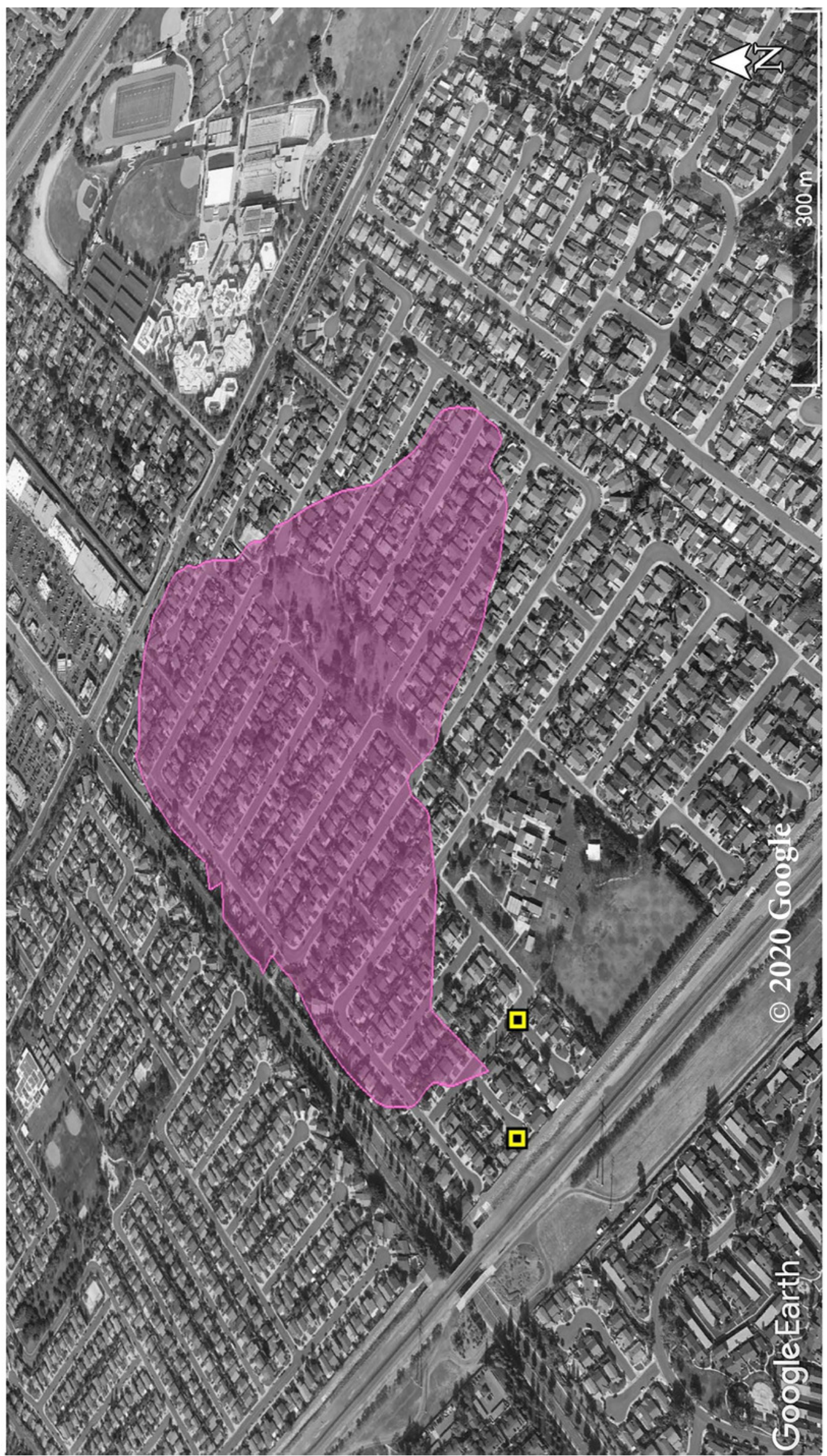


Figure 3

Site 3 surveyed for A. sagrei and S. occidentalis.

The red polygon represents the minimum convex polygon where $A$. sagrei was found in the invaded areas. The green dots represent $S$. occidentalis individuals detected during these surveys. The blue polygon identifies a plant nursery. 


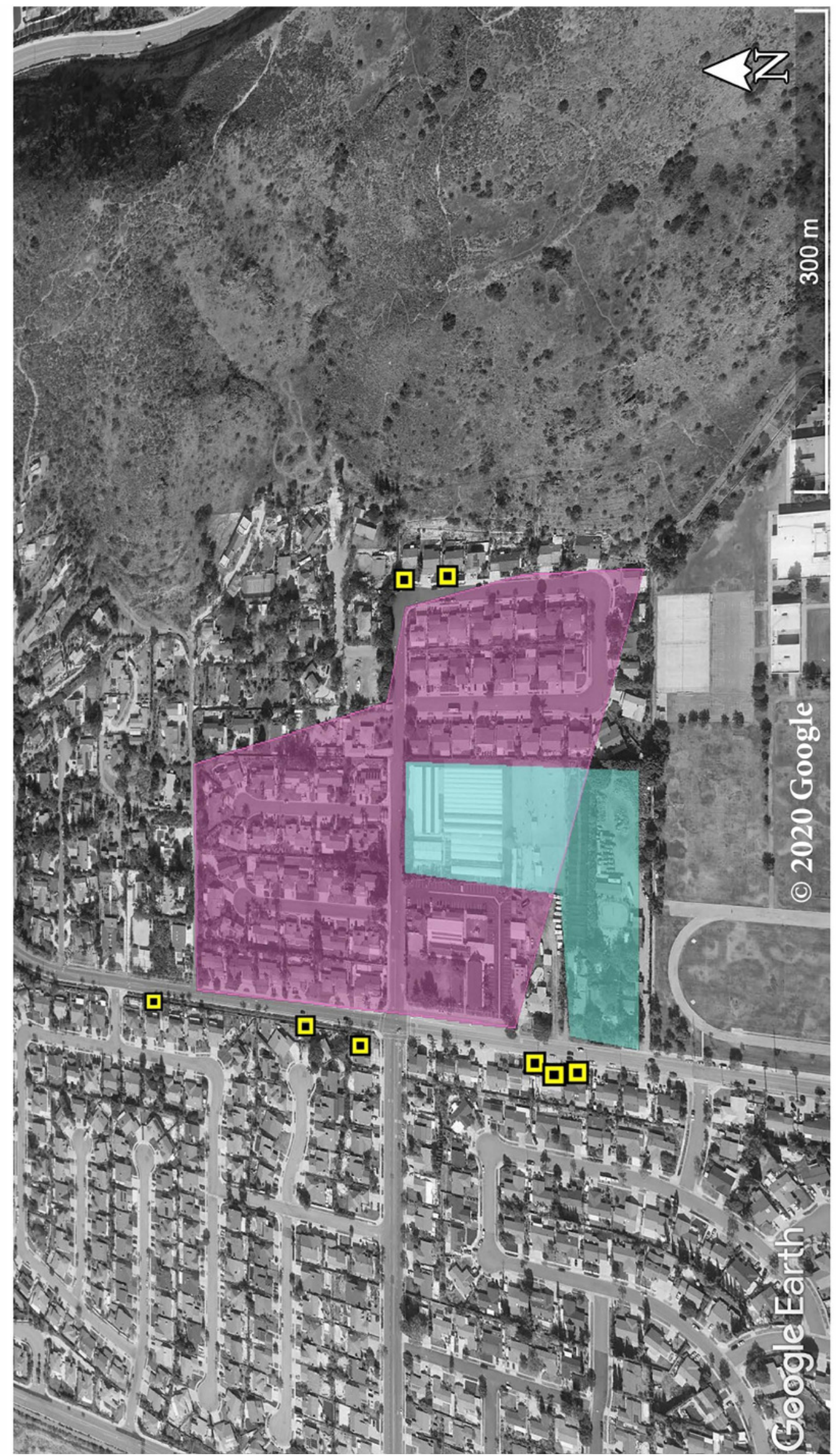


Figure 4

Site 4 surveyed for $A$. sagrei and S. occidentalis.

The red polygon represents the minimum convex polygon where $A$. sagrei was found in the invaded areas. No S. occidentalis individuals detected during these surveys. The blue polygon identifies a plant nursery. 


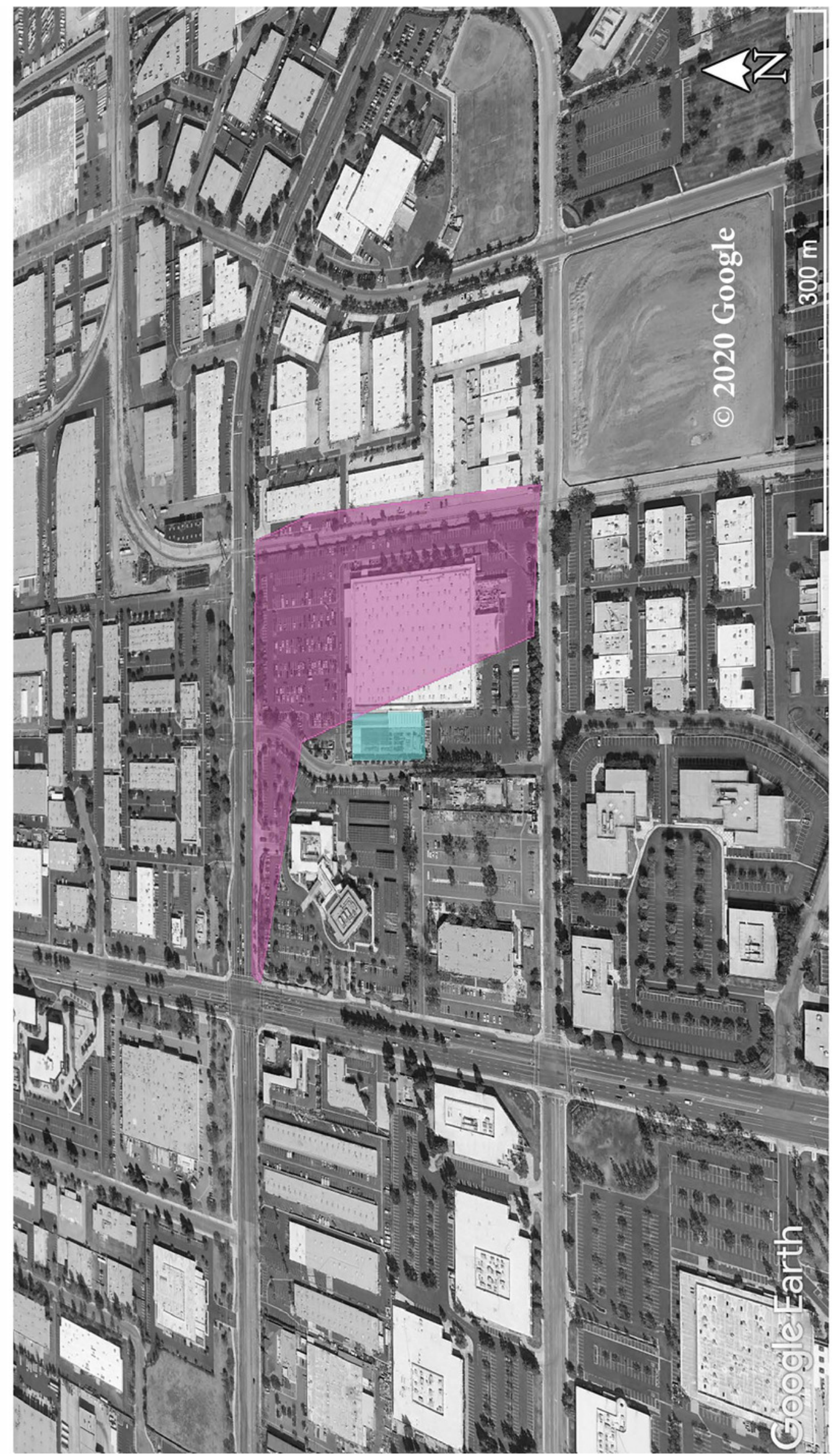




\section{Figure 5}

Site 5 surveyed for $A$. sagrei and S. occidentalis.

The red polygon represents the minimum convex polygon where $A$. sagrei was found in the invaded areas. This figure illustrates all of the anole locations (red dots), each dot could represent up to three observations of anoles. The green dots represent up to three $S$. occidentalis individuals detected during these surveys. The blue polygon identifies a plant nursery. 


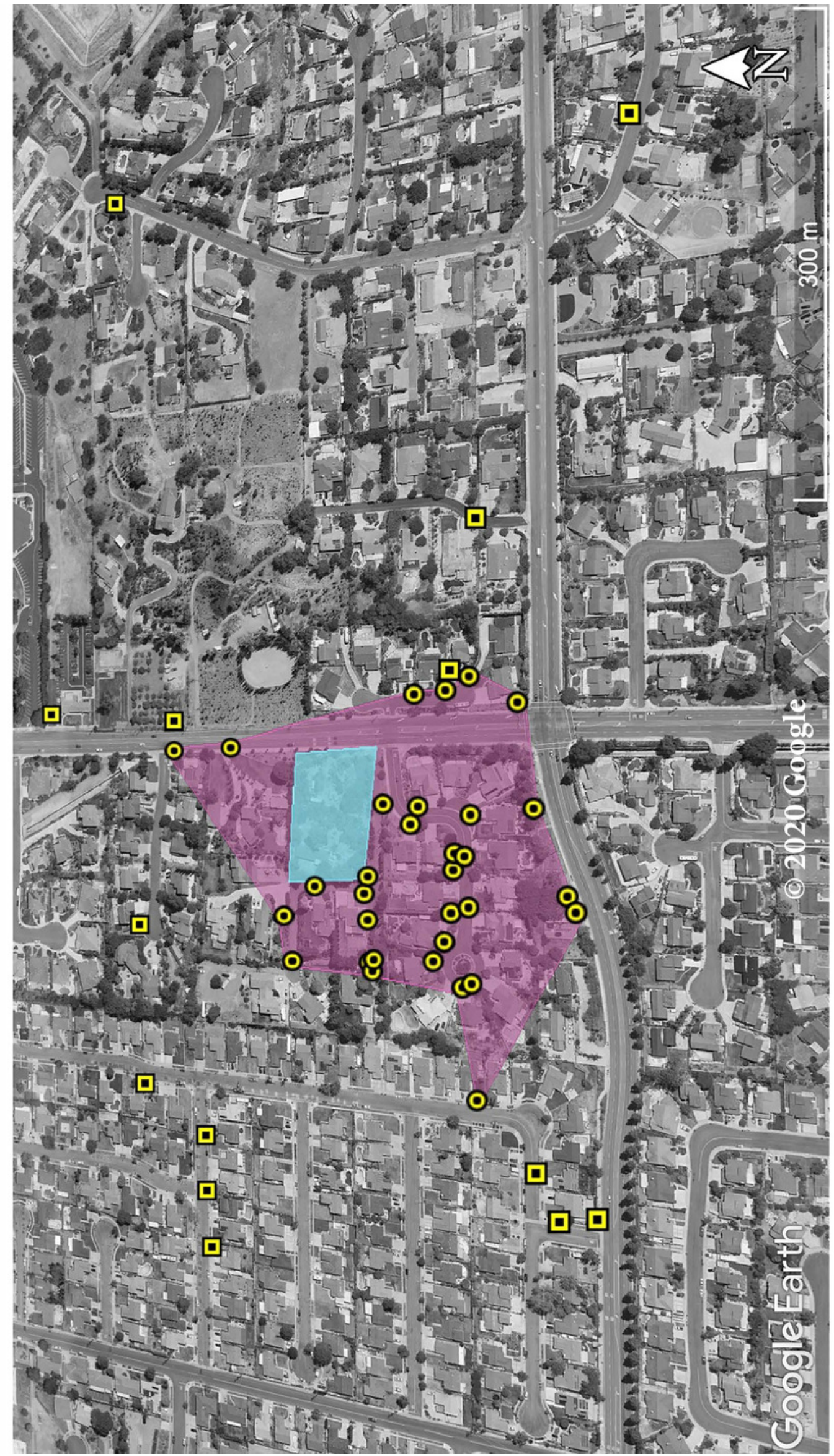

